\title{
New terpenoids from the roots of Jatropha curcas
}

\author{
YANG YuanFeng $^{1,2}$, LIU JieQing ${ }^{1}$, LI XuYang ${ }^{1,2}$, LIU EnQian $^{1}$, LI ZhongRong ${ }^{1} \&$ \\ QIU MingHua ${ }^{1,2 *}$ \\ ${ }^{1}$ State Key Laboratory of Phytochemistry and Plant Resources in West China, Kunming Institute of Botany, Chinese Academy of Sciences, \\ Kunming 650201, China; \\ ${ }^{2}$ University of Chinese Academy of Sciences, Beijing 100049, China
}

Received November 2, 2012; accepted December 12, 2012; published online January 10, 2013

\begin{abstract}
Two new sesquiterpenoids, (1S,2R)-dihydroxycycloax-4(15)-ene (1), 14-dehydroxyl daucucarotol (2), and one new rhamnofalane diterpenoid, 2-hydroxy-3-dehydroxycaniojane (3), together with two known compounds, curcusone D (4) and curcusone C (5), were isolated from the roots of Jatropha curcas. The chemical structures of these compounds were established by chemical methods and extensive 1D- and 2D-NMR spectroscopic data analyses.
\end{abstract}

Jatropha curcas, sesquiterpenoids, diterpenoid

Citation: $\quad$ Yang Y F, Liu J Q, Li X Y, et al. New terpenoids from the roots of Jatropha curcas. Chin Sci Bull, 2013, 58: 1115-1119, doi: 10.1007/s11434-012-5655-4

Jatropha curcas (Euphorbiaceae) is indigenous to southwest and southeast China. The plant has been used as folk medicine for the treatment of injuries and swelling, fracture, skin itching, eczema, and acute gastroenteritis embolism [1]. Besides, the seeds containing $30 \%$ oil can be processed to produce a high-quality biodiesel fuel, usable in a standard diesel engine. And that is why Jatropha curcas was greatly focused as biodiesel source all over the world. The plants of genus Jatropha, mainly distributed in tropical and subtropical America [2]. The chemical constituents from this genus were plentiful, covered of diterpenoids, sesquiterpenoids, lignans and coumarins, flavonoids, and some others [3], and some of the diterpenoids have been proved to be effective as anti-inflammatory [4], antiproliferation [5,6], antiplasmodial [7], antituberculosis [8], antitumor [8,9], and cytotoxic activities [10].

Lately, several structurally interesting diterpenoids were isolated from this plant $[9,11,12]$. Its potential medicinal value and the diverse constituents prompted us to initiate the chemical investigation of $J$. curcas.

Our phytochemical study from the methanol extracts of roots of $J$. curcas led to the isolation of five compounds

*Corresponding author (email: mhchiu@mail.kib.ac.cn)
(1-5) (Figure 1), including two new sesquiterpenes, (1S, 2R)-dihydroxycycloax-4(15)-ene (1) and 14-dehydroxyl daucucarotol (2), one new rhamnofalane endoperoxide, 2-hydroxy-3-dehydroxy caniojane (3), and two known

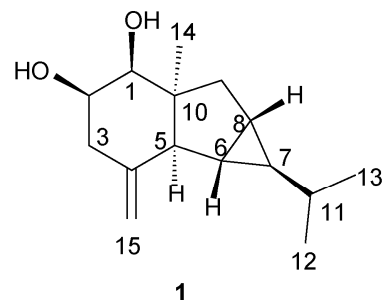<smiles>C[C@H]1C[C@@H](C(C)(C)O)[C@@H](C)[C@H](C)[C@H]1O</smiles>

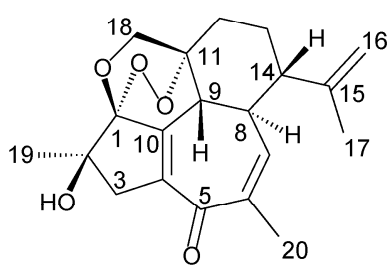

3

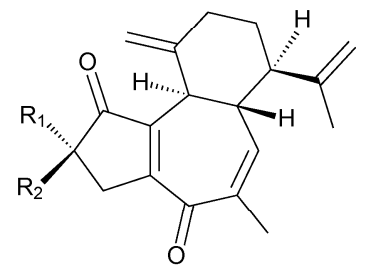

$\begin{array}{lll}\mathrm{R}_{1} & \mathrm{R}_{2}\end{array}$

$4 \mathrm{CH}_{3} \mathrm{OH}$

$5 \mathrm{OH} \quad \mathrm{CH}_{3}$
Figure 1 Structures of compounds 1-5. 
compounds, curcusone D (4) [13] and curcusone C (5) [13]. This paper deals with the isolation and structure elucidation of new compounds $\mathbf{1}-\mathbf{3}$.

\section{Experimental}

\subsection{General experimental procedures}

UV spectra were obtained in $\mathrm{MeOH}$ with a Shimadzu double-beam 22210A spectrophotometer; Optical rotations were measured on a SEPA-300 polarimeter; IR spectra were obtained using a Bio-Rad FTS-135 infrared spectrometer with $\mathrm{KBr}$ pellets; NMR spectra were recorded on Bruker DRX-600 (600/150 MHz) spectrometers with TMS as internal standard; high resolution electrospray ionization mass spectroscopy (HRESIMS) and low resolution ESIMS were recorded on an APIQSTAR time-of-flight mass spectrometer while high resolution electron impact mass spectroscopy (HREIMS) were measured on a VG Auto Spec-3000 mass spectrometer; Semipreparative HPLC was performed on an Agilent 1100 apparatus equipped with a diode-array detector and a YMC-PackProC ${ }_{18} \mathrm{RS}$ (YMC, $250 \mathrm{~mm} \times 10 \mathrm{~mm}, 5$ $\mu \mathrm{m})$ column; column chromatography was performed on silica gel (200-300 mesh, Qingdao Marine Chemical Factory, Qingdao, China), Lichroprep RP-18 gel (40-63 $\mu \mathrm{m}$, Merck, Darmstadt, Germany), Sephadex LH-20 (General Electric Company, Fairfield, CT); Fractions were monitored by TLC, and spots were visualized by heating silica gel plates sprayed with $10 \% \mathrm{H}_{2} \mathrm{SO}_{4}$.

\subsection{Plant material}

The roots of Jatropha curcas were collected from E-Shan county, Yunnan Province, China, in July 2010, and identified by Prof. Hua Peng. A voucher specimen (No. KIB 20100701) was deposited at the State Key Laboratory of Phytochemistry and Plant Resources in West China, Kunming Institute of Botany, Chinese Academy of Sciences.

\subsection{Extraction and isolation}

The dried and powdered roots of $J$. curcas $(5 \mathrm{~kg})$ were refluxed three times with $95 \%$ aqueous $\mathrm{MeOH}$ at room temperature. The combined $\mathrm{MeOH}$ extracts were concentrated under reduced pressure, and then partitioned between $\mathrm{CHCl}_{3}$ and $\mathrm{H}_{2} \mathrm{O}$. The $\mathrm{CHCl}_{3}$ layer (130 g) was subjected to a macroporous resin gel column chromatography eluted with a gradient solvent system of $\mathrm{MeOH}-\mathrm{H}_{2} \mathrm{O}$ to yield $80 \%$ $\mathrm{MeOH}-\mathrm{H}_{2} \mathrm{O}$ extract, The $80 \% \mathrm{MeOH}-\mathrm{H}_{2} \mathrm{O}$ extract $(70 \mathrm{~g})$ was chromatographed on silica gel $\mathrm{CC}$ with $\mathrm{Me}_{2} \mathrm{CO}-\mathrm{PE}$ mixtures $(1: 15,1: 10,1: 5$, and 1:1) to get four fractions (Fr.1, Fr.2, Fr.3, and Fr.4). Fr.3 (10 g) was separated on an ODS column eluting with $\mathrm{MeOH}-\mathrm{H}_{2} \mathrm{O}(45 \%, 60 \%$, and $70 \%)$ to give subfractions Fr.3.1-Fr.3.3. Subfraction Fr.3.1 (3 g) was further isolated and purified by silica gel column (PE-
$\left.\mathrm{Me}_{2} \mathrm{CO}, 10: 1\right)$, Sephadex LH-20 (MeOH), Preparative TLC $\left(\mathrm{CH}_{3} \mathrm{Cl}-\mathrm{Me}_{2} \mathrm{CO}\right)$ to yield $\mathbf{1}(10 \mathrm{mg})$ and $2(7 \mathrm{mg})$. Fr.1 $(20 \mathrm{~g})$ was further fractionized on an ODS column eluting with $\mathrm{MeOH}-\mathrm{H}_{2} \mathrm{O}(55 \%, 65 \%$, and $80 \%)$ to afford subfractions Fr.1.1-Fr.1.3. Subfraction Fr.1.3 (5 g) was further isolated and purified by silica gel column ( $\mathrm{PE}-\mathrm{Me}_{2} \mathrm{CO}$ ), semipreparative HPLC $\left(\mathrm{CH}_{3} \mathrm{CN}-\mathrm{H}_{2} \mathrm{O}\right)$ to afford $\mathbf{3}(1.3 \mathrm{mg})$. Fr.2 $(20 \mathrm{~g})$ was further fractionized on an ODS column eluting with $\mathrm{MeOH}-\mathrm{H}_{2} \mathrm{O}(50 \%, 62 \%$, and $75 \%)$ to afford subfractions Fr.2.1-Fr.2.3. Subfraction Fr.2.2 ( $8 \mathrm{~g})$ was further isolated and purified by silica gel column (PE-Me $\left.{ }_{2} \mathrm{CO}\right)$ to afford 4 $(40 \mathrm{mg})$ and $\mathbf{5}(30 \mathrm{mg})$.

(i) (1S,2R)-Dihydroxycycloax-4(15)-ene (1). Yellow, oil; $[\alpha]_{\mathrm{D}}^{25}=-33.2\left(c 1.0, \mathrm{CHCl}_{3}\right)$; IR (KBr) $v_{\max }: 3350,2958$, 2953, 2870, $1047 \mathrm{~cm}^{-1}$; ${ }^{1} \mathrm{H}$ and ${ }^{13} \mathrm{C}$ NMR data see Table 1; positive ESIMS (pos.): $\mathrm{m} / z 259\left[\mathrm{M}+\mathrm{Na}^{+}\right.$; positive HRESIMS (pos.): $\mathrm{m} / \mathrm{z} 259.1668\left[\mathrm{M}+\mathrm{Na}^{+}\right.$(calcd for $\mathrm{C}_{15} \mathrm{H}_{24} \mathrm{O}_{2}[\mathrm{M}+\mathrm{Na}]^{+}, m / z$ 259.1673).

(ii) 14-Dehydroxyl daucucarotol (2). White, amorphous powder; $[\alpha]_{\mathrm{D}}^{25}=+2.8\left(c 1.0, \mathrm{CHCl}_{3}\right)$; IR $(\mathrm{KBr}) v_{\max }: 3340$, 2950, 2933, 2865, $1056 \mathrm{~cm}^{-1}$; ${ }^{1} \mathrm{H}$ and ${ }^{13} \mathrm{C}$ NMR data see Table 1; positive ESIMS (pos.): $m / z 263[\mathrm{M}+\mathrm{Na}]^{+}$; positive HRESIMS (pos.): $\mathrm{m} / \mathrm{z}$ 263.1985 [M $+\mathrm{Na}]^{+}$(calcd for $\mathrm{C}_{15} \mathrm{H}_{28} \mathrm{O}_{2}[\mathrm{M}+\mathrm{Na}]^{+}, m / z$ 263.1987).

(iii) 2-Hydroxy-3-dehydroxycaniojane (3). White, crystalline solid; $[\alpha]_{\mathrm{D}}^{25}=-63.2(c 0.03, \mathrm{MeOH}) ; \mathrm{UV}(\mathrm{MeOH})$ $\lambda_{\max }(\log \varepsilon): 254$ (3.00), 202 (5.19) nm; IR (KBr) $v_{\max }: 3440$, 1711, 1628, $1452 \mathrm{~cm}^{-1} ;{ }^{1} \mathrm{H}$ and ${ }^{13} \mathrm{C}$ NMR data see Table 1; positive TOF MS $\mathrm{m} / \mathrm{z} 345[\mathrm{M}+\mathrm{H}]^{+}$; positive HREIMS $\mathrm{m} / \mathrm{z}$ $367.1742[\mathrm{M}+\mathrm{Na}]^{+}$(calcd for $\mathrm{C}_{20} \mathrm{H}_{24} \mathrm{O}_{5}[\mathrm{M}+\mathrm{Na}]^{+}, \mathrm{m} / \mathrm{z}$ 367.1521).

\section{Results and discussion}

Compound 1 was obtained as yellowish oil. Its molecular formula was determined as $\mathrm{C}_{15} \mathrm{H}_{24} \mathrm{O}_{2}$ by positive HRESIMS $m / z 259.1668[\mathrm{M}+\mathrm{Na}]^{+}$(calcd for $\mathrm{C}_{15} \mathrm{H}_{24} \mathrm{O}_{2}[\mathrm{M}+\mathrm{Na}]^{+}$, $\mathrm{m} / \mathrm{z}$ 259.1673). The IR spectrum exhibited absorption bands for $\mathrm{OH}$ group $\left(3350 \mathrm{~cm}^{-1}\right)$ and an olefinic function (1047 $\mathrm{cm}^{-1}$ ). The ${ }^{1} \mathrm{H},{ }^{13} \mathrm{C}$ NMR, and DEPT (Distortionless enhancement by polarization transfer) data of $\mathbf{1}$ (Table 1) showed the presence of three methyls (two geminal methyls), three methylenes (one olefinic), seven methines (two oxygenated), and two quaternary carbons (one olefinic). The above-mentioned data, together with the evidence of four degrees of unsaturation suggested that $\mathbf{1}$ was quite similar to $(1 R, 2 R)$-dihydroxycycloax-4(15)-ene [14].

Comprehensive analysis of HSQC (heteronuclear single quantum correlation) and ${ }^{1} \mathrm{H}-{ }^{1} \mathrm{H}$ COSY (correlation spectrometry) spectra of $\mathbf{1}$ allowed the establishment of one structural fragment as drawn in blue bold lines in Figure 2(a). One exocyclic double bond was evident from ${ }^{1} \mathrm{H}$ NMR signal at $\delta_{\mathrm{H}} 4.98$ and ${ }^{13} \mathrm{C}$ NMR signals at $\delta_{\mathrm{C}} 106.5(\mathrm{t})$. In the 
Table $1{ }^{1} \mathrm{H}$ and ${ }^{13} \mathrm{C}$ NMR data of $\mathbf{1}-\mathbf{3}$ in $\mathrm{CDCl}_{3}(600$ and $150 \mathrm{MHz}$, respectively)

\begin{tabular}{|c|c|c|c|c|c|c|}
\hline & & 1 & & 2 & & 3 \\
\hline & $\delta_{\mathrm{C}}$ & $\delta_{\mathrm{H}}($ mult, $J$ in $\mathrm{Hz})$ & $\delta_{\mathrm{C}}$ & $\delta_{\mathrm{H}}($ mult,$J$ in $\mathrm{Hz})$ & $\delta_{\mathrm{C}}$ & $\delta_{\mathrm{H}}($ mult,$J$ in $\mathrm{Hz})$ \\
\hline 1 & 82.4 (d) & $3.72(\mathrm{~d}, 8.5)$ & $39.5(\mathrm{~d})$ & $2.02-2.05(\mathrm{~m})$ & $103.8(\mathrm{~s})$ & \\
\hline 2 & 72.7 (d) & $4.12(\mathrm{ddd}, 10.6,8.8,6.5)$ & $34.6(t)$ & $\begin{array}{l}1.60-1.64(\mathrm{~m}) \\
1.29-1.32(\mathrm{~m})\end{array}$ & $77.6(\mathrm{~s})$ & \\
\hline 3 & $44.4(t)$ & $\begin{array}{c}2.88(\mathrm{dd}, 13.2,7.5) \\
2.43(\mathrm{brdd}, 13.2,5.9)\end{array}$ & $27.3(t)$ & $1.96-1.99(\mathrm{~m})$ & $43.9(t)$ & $\begin{array}{c}2.80-2.84(\mathrm{~m}) \\
2.63(\mathrm{dd}, 16.1,4.1)\end{array}$ \\
\hline 4 & $145.8(\mathrm{~s})$ & & $24.1(\mathrm{t})$ & $\begin{array}{c}2.22(\mathrm{ddd}, 22.6,15.1,7.6) \\
1.27-1.30(\mathrm{~m})\end{array}$ & $138.9(\mathrm{~s})$ & \\
\hline 5 & $58.6(\mathrm{~d})$ & $1.88(\mathrm{~d}, 3.5)$ & $53.0(\mathrm{~d})$ & $2.20(\mathrm{~m})$ & $193.6(\mathrm{~s})$ & \\
\hline 6 & 32.7 (d) & $0.85-0.94(\mathrm{~m})$ & $74.3(\mathrm{~s})$ & & $137.1(\mathrm{~s})$ & \\
\hline 7 & 48.4 (d) & $0.50-0.55(\mathrm{~m})$ & $48.9(\mathrm{t})$ & $\begin{array}{l}1.88(\mathrm{~m}) \\
2.24(\mathrm{~m})\end{array}$ & $138.6(d)$ & $5.94(\mathrm{dd}, 4.0,1.5)$ \\
\hline 8 & 25.5 (d) & $1.18-1.24(\mathrm{~m})$ & $51.1(\mathrm{~d})$ & $1.93(\mathrm{~m})$ & 35.3 (d) & $2.87(\mathrm{~d}, 10.8)$ \\
\hline 9 & $43.5(t)$ & $\begin{array}{l}2.24(\mathrm{dd}, 12.1,6.6) \\
1.25-1.27(\mathrm{~m})\end{array}$ & $30.2(t)$ & $\begin{array}{l}1.70-1.73(\mathrm{~m}) \\
1.54-1.58(\mathrm{~m})\end{array}$ & $47.2(d)$ & $2.45-2.49(\mathrm{~m})$ \\
\hline 10 & $59.5(\mathrm{~s})$ & & $41.0(\mathrm{~d})$ & $1.81-1.84(\mathrm{~m})$ & $147.3(\mathrm{~s})$ & \\
\hline 11 & 24.2 (d) & $1.32-1.37(\mathrm{~m})$ & $73.4(\mathrm{q})$ & & $69.8(\mathrm{~s})$ & \\
\hline 12 & $22.2(\mathrm{q})$ & $0.90(\mathrm{~d}, 4.5)$ & $28.7(q)$ & $1.37(\mathrm{~s})$ & $32.2(\mathrm{t})$ & $\begin{array}{c}1.53-1.55 \text { (overlapped) } \\
1.36(\mathrm{~m})\end{array}$ \\
\hline 13 & $22.0(\mathrm{q})$ & $0.93(\mathrm{~d}, 4.5)$ & $26.4(\mathrm{q})$ & $1.32(\mathrm{~s})$ & $25.7(t)$ & $\begin{array}{l}1.88(\mathrm{ddd}, 9.1,4.5,2.5) \\
1.53-1.55 \text { (overlapped) }\end{array}$ \\
\hline 14 & $15.9(\mathrm{q})$ & $1.18(\mathrm{~s})$ & $15.9(\mathrm{q})$ & $0.85(\mathrm{~d}, 7.0)$ & $51.3(\mathrm{~d})$ & $2.01-2.05(\mathrm{~m})$ \\
\hline 15 & $106.5(\mathrm{t})$ & $4.98(\mathrm{dd}, 3.7,1.4)$ & $22.4(q)$ & $1.34(\mathrm{~s})$ & $146.5(\mathrm{~s})$ & \\
\hline 16 & & & & & $113.3(\mathrm{t})$ & $4.80,4.77(\mathrm{~s})$ \\
\hline 17 & & & & & $18.9(\mathrm{q})$ & $1.60(\mathrm{~s})$ \\
\hline 18 & & & & & $70.0(t)$ & $\begin{array}{l}4.01-4.04(\mathrm{~m}) \\
3.41-3.43(\mathrm{~m})\end{array}$ \\
\hline 19 & & & & & $23.6(q)$ & $1.39(\mathrm{~s})$ \\
\hline 20 & & & & & $20.5(\mathrm{q})$ & $1.76(\mathrm{~s})$ \\
\hline
\end{tabular}

(a)

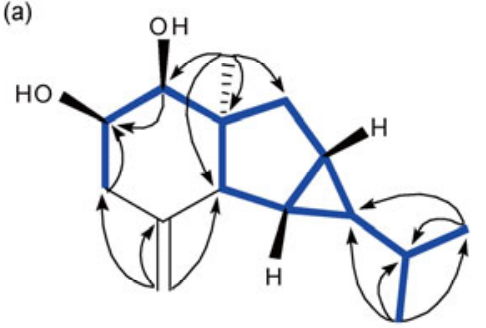

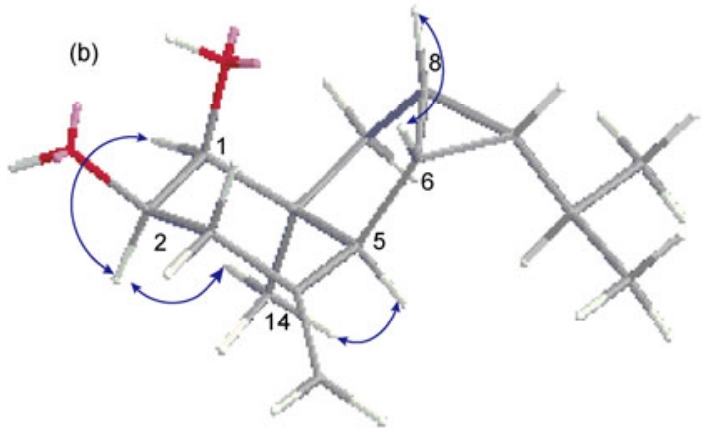

Figure 2 The ${ }^{1} \mathrm{H}-{ }^{1} \mathrm{H}$ COSY $(-)$, key HMBC correlations $(\mathrm{H} \rightarrow \mathrm{C})($ a), and key ROESY correlations $(\curvearrowleft)$ (b) of $\mathbf{1}$.

HMBC spectrum of $\mathbf{1}$, the correlations from the olefinic proton signal $\delta_{\mathrm{H}} 4.98$ to $\mathrm{C}-3, \mathrm{C}-4$, and $\mathrm{C}-5$ indicated the assignment of the exocyclic double bond between $\mathrm{C}-4$ and $\mathrm{C}-15$. The HMBC (heteronuclear multiple bond correlation) correlations from the quaternary methyl signal at $\delta_{\mathrm{H}} 1.18$ to C-1, C-5, C-9, and C-10, and from one of the methylene proton signals at $\delta_{\mathrm{H}} 2.88(\mathrm{dd}, 13.2,5.9)$ to $\mathrm{C}-1$ and $\mathrm{C}-2$ suggested the presence of hydroxyl groups at C-1 and C-2, respectively. Moreover, the existence of strong NOE correlations between $\mathrm{H}-1 / \mathrm{H}-2, \mathrm{H}-2 / \mathrm{H}_{3}-14, \mathrm{H}_{3}-14 / \mathrm{H}-5$, and $\mathrm{H}-6 / \mathrm{H}-8$ in the ROESY (rotating frame overhauser effect spectroscopy) spectrum of $\mathbf{1}$ (Figure 2(b)) suggested that $\mathrm{OH}-1$ was $\beta$-oriented, which was the only difference between 1 and $(1 R, 2 R)$-dihydroxycycloax-4(15)-ene. Consequently, the structure of $\mathbf{1}$ was deduced as $(1 S, 2 R)$-dihydroxycycloax-4(15)-ene. 
Compound 2 obtained as white powder, possessed a molecular formula of $\mathrm{C}_{15} \mathrm{H}_{28} \mathrm{O}_{2}$, as evidenced by HRESIMS at $m / z 263.1985[\mathrm{M}+\mathrm{Na}]^{+}$(calcd for $\mathrm{C}_{15} \mathrm{H}_{28} \mathrm{O}_{2}[\mathrm{M}+\mathrm{Na}]^{+}$, $\mathrm{m} / \mathrm{z}$ 263.1987), in accordance with two degrees of unsaturation. Importantly, the absence of any olefinic moieties in the ${ }^{13} \mathrm{C}$ NMR spectrum required the presence of two rings to satisfy the degrees of unsaturation.

The ${ }^{13} \mathrm{C}$ NMR and DEPT (Table 1) data of 2 exhibited four methyls, five methylenes, four methines, and two oxygenated quaternary carbons. These spectral features were closely related to those of daucucarotol [15], except for a tertiary methyl signal in $\mathbf{2}$ instead of an oxygenated methylene signal in daucucarotol. The HMBC spectrum of $\mathbf{2}$ displayed cross-peaks from the doublet methyl signal at $\delta_{\mathrm{H}}$ 0.85 to $\mathrm{C}-1, \mathrm{C}-2$, and $\mathrm{C}-10$, which suggested that the doublet methyl group located at $\mathrm{C}-1$. The planar structure of $\mathbf{2}$ was further established from the ${ }^{1} \mathrm{H}-{ }^{1} \mathrm{H}$ COSY and HMBC spectra (Figure 3(a)).

The ROESY (Figure 3(b)) correlations of Me-14/H-5, $\mathrm{H}-10 / \mathrm{H}-8$, and $\mathrm{H}-10 / \mathrm{Me}-15$ suggested that the $\mathrm{H}-1, \mathrm{H}-8$, $\mathrm{Me}-15$, and $\mathrm{H}-11$ were of $\beta$-orientation. Ultimately, the structure of 2 was determined and named 14-dehydroxyl daucucarotol.

Compound $\mathbf{3}$ was obtained as crystalline solid. The HREIMS spectrum gave an $[\mathrm{M}+\mathrm{Na}]^{+}$ion at $\mathrm{m} / z$ 367.1742, corresponding to the molecular formula $\mathrm{C}_{20} \mathrm{H}_{24} \mathrm{O}_{5}$. The IR spectrum displayed absorption bands for unsaturated carbonyl $\left(1658 \mathrm{~cm}^{-1}\right)$ and olefinic $\left(1628 \mathrm{~cm}^{-1}\right)$ groups. The ${ }^{1} \mathrm{H}$, ${ }^{13} \mathrm{C}$, and DEPT (Table 1) NMR data of $\mathbf{3}$ showed the pres- ence of three methyls, one oxymethylene $\left(\delta_{\mathrm{C}} 70.0\right)$, one dioxygenated carbon $\left(\delta_{\mathrm{C}} 103.8\right)$, two oxygenated carbon, a terminal double-bond, two double-bonds, and a keto carbonyl carbon $\left(\delta_{\mathrm{C}} 193.6\right)$. These data showed that 3 was similar with caniojane [16]. The key difference was that one oxygenated quaternary carbon signal in $\mathbf{3}$ instead of an oxygenated methine in caniojane. Meanwhile, there was no doublet methyl signal in ${ }^{1} \mathrm{H}$ NMR spectrum. Above data indicated that a hydroxyl group would attach to C-2, which was confirmed by the HMBC correlations from $\mathrm{H}_{3}-19$ to C-1, C-2 $\left(\delta_{\mathrm{C}} 77.6, \mathrm{~s}\right)$, and C-3.

The planar structure of $\mathbf{3}$ was further determined by the correlations in the HMBC and ${ }^{1} \mathrm{H}-{ }^{1} \mathrm{H}$ COSY spectra (Figure 4(a)). The relative configuration of Me-19 was determined as $\alpha$-oriented on the basis of the chemical shift of C-19 at $\delta_{\mathrm{C}}$ 23.6 and were consistent with those reported for curcusone $\mathrm{C}$ [13]. The relative configuration of the peroxy bond between $\mathrm{C}-1$ and $\mathrm{C}-11$ was assigned as $\beta$ by the correlations between $\mathrm{H}_{2}-18$ and $\mathrm{H}-9$ in the ROESY (Figure 4(b)) spectrum. Finally the structure of $\mathbf{3}$ was proposed to be 2-hydroxy-3-dehydroxycaniojane.

Caniojane and 1,11-bisepicaniojane [16,17], having peroxide bridge, performed certain antimalarial activity [18]. Well-known to all, artemisinin (Figure 5) is the antimalarial drug containing peroxide bridge, and the peroxy bond is necessary for the activity based on the structure-activity relationships. So, whether compound $\mathbf{3}$ with peroxide bridge playing a similar role in the resistance of plasmodium activity needs further study. (a)

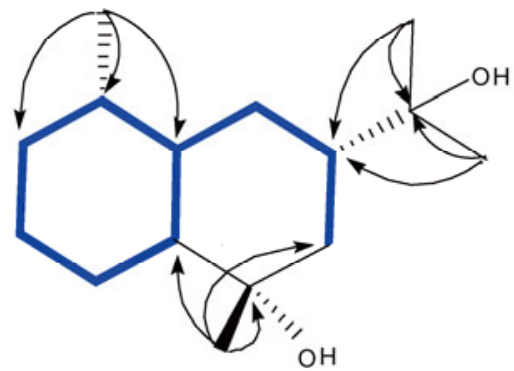

(b)

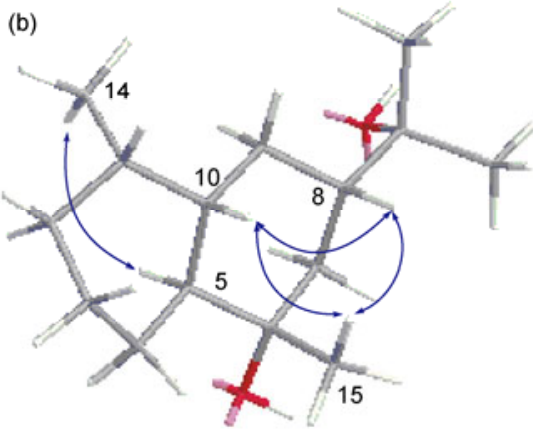

Figure 3 The ${ }^{1} \mathrm{H}_{-}{ }^{1} \mathrm{H}$ COSY $(-)$, key HMBC correlations $(\mathrm{H} \rightarrow \mathrm{C})(\mathrm{a})$, and key ROESY correlations $(\curvearrowleft)(\mathrm{b})$ of 2.
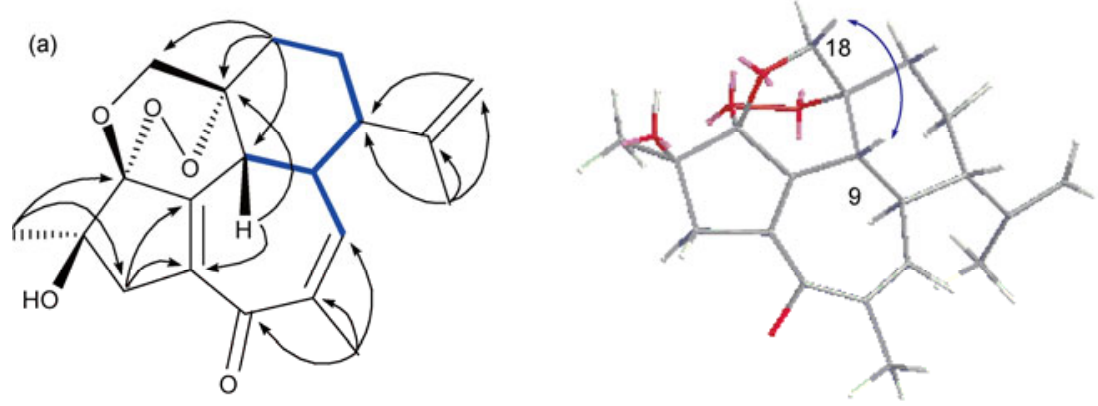

Figure 4 The ${ }^{1} \mathrm{H}^{-1} \mathrm{H}$ COSY $(-)$, key HMBC correlations $(\mathrm{H} \rightarrow \mathrm{C})(\mathrm{a})$, and key ROESY correlations $(\overbrace{}^{\circ}(\mathrm{b})$ of 3. 


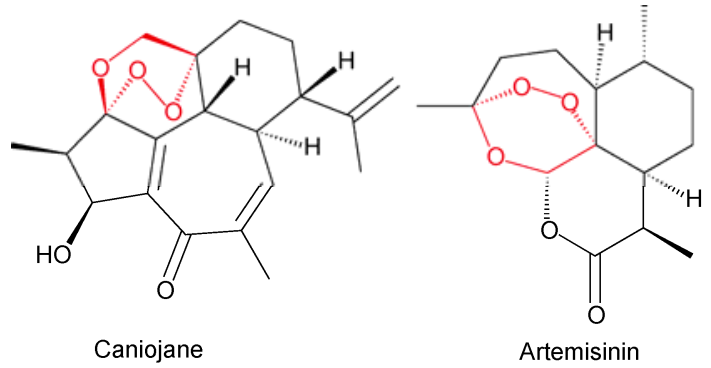

Figure 5 Structures of caniojane and artemisinin.

The author is grateful to Prof. Hua Peng of the Kunming Institute of Botany, Chinese Academy of Sciences, for the identification of the plant. This work was surppoted by the Key Projects of the Chinese Ministry of Science and Technology (2007BAD32B01-03 and SB2007FY400), the National Natural Science Foundation of China (81202437) and the National Knowledge Innovation Program of Chinese Academy of Sciences (KSCX2-YW-G-038).

1 The Editor committee, Flora Repubulicae Popularis Sinicae, the Chinese Academy of Sciences. Flora Repubulicae Popularis Sinicae. Beijing: Science Press, 2004. 147-149

2 Institute of Botany, the Chinese Academy of Sciences. Chinese Higher Plant Family Genera Retrieval Table. Beijing: Science Press, 1979. 253

3 Zhang X P, Zhang M L, Su X H, et al. Chemical constituents of the plants from genus Jatropha. Chem Biodivers, 2009, 6: 2166-2183

4 Pertino M, Schmeda-Hirschmann G, Rodriguez J A, et al. Gastroprotective effect and cytotoxicity of semisynthetic jatropholone derivatives. Plant Med, 2007, 73: 1095-1100

5 Theoduloz C, Rodriguez J A, Pertino M, et al. Antiproliferative activity of the diterpenes jatrophone and jatropholone and their derivatives. Plant Med, 2009, 75: 1520-1522

6 Goncalves de Moraes V L, Rumjanek V M, Calixto J B. Jatrophone and 12-O-tetradecanoyl phorbol-13-acetate antagonism of stimulation of natural killer activity and lymphocyte proliferation. Eur J Pharmacol, 1996, 312: 333-339

7 Sutthivaiyakit S, Mongkolvisut W, Prabpai S, et al. Sesquiterpenes, and a Sesquiterpene-Coumarin Conjugate from Jatropha integerrima. J Nat Prod, 2009, 72: 2024-2027

8 Taylor M D, Smith III Amos B, Furst G T, et al. New antileukemic jatrophone derivatives from Jatropha gossypiifolia: Structural and stereochemical assignment through nuclear magnetic resonance spectroscopy. J Am Chem Soc, 1983, 105: 3177-3183

9 Kupchan S M, Sigel C W, Matz M J, et al. Jatrophone, a novel macrocyclic diterpeniod tumor inhibitor from Jatropha gossyiifolia. J Am Chem Soc, 1970, 92: 4476-4477

10 Wang X C, Zheng Z P, Gan X W, et al. Jatrophalactam, a novel diterpenoid lactam isolated from Jatropha curcas. Org Lett, 2009, 11: 5522-5524

11 Chianese G, Fattorusso E, Aiyelaagbe O O, et al. Spirocurcasone, a diterpenoid with a novel carbon skeleton from Jatropha curcas. Org Lett, 2011, 13: 316-319

12 Liu J Q, Yang Y F, Wang C F, et al. Three new diterpenes from Jatropha curcas. Tetrahedron, 2012, 68: 972-976

13 Naengchomnong W, Thebtaranonth Y, Wiriyachitra P, et al. Isolation and structure determination of two novel lathyranes from Jatropha curcus. Tetrahedron Lett, 1986, 27: 5675-5678

14 Garcia A, Delgado G. Uncommon sesquiterpenoids and new triterpenoids from Jatropha neopauciflora (Euphorbiaceae). Helv Chim Acta, 2006, 89: 16-29

15 Fu H W, Zhang L, Yi T, et al. A new sesquiterpene from the fruits of Daucus carota L. Molecule, 2009, 14: 2862-2867

16 Jakupovic J, Grenz M, Schmeda-Hirschmann G. Rhamnofolane derivatives from Jatropha grossidentata. Phytochemistry, 1988, 27: 2997-2998

17 Sutthivaiyakit S, Mongkolvisut W, Ponsitipiboon P, et al. A novel 8,9-seco-rhamnofolane and a new rhamnofolane endoperoxide from Jatropha integerrima roots. Tetrahedron Lett, 2003, 44: 3637-3640

18 Sutthivaiyakit S, Mongkolvisut W, Prabpai S, et al. Diterpenes, Sesquiterpenes, and a sesquiterpene-coumarin conjugate from Jatropha integerrima. J Nat Prod, 2009, 72: 2024-2027

Open Access This article is distributed under the terms of the Creative Commons Attribution License which permits any use, distribution, and reproduction in any medium, provided the original author(s) and source are credited. 